\section{Commentary on: Self-care self-efficacy, religious participation and depression as predictors of post-stroke self-care among underserved ethnic minorities}

\author{
Nicola Luigi Bragazzi \\ School of Public Health, Department \\ of Health Sciences, Genoa, Italy
}

Robertson et al. ${ }^{1}$ investigated self-care selfefficacy, religiosity/spirituality (specifically, religious participation) and depression in a sample of 52 ethnic minority under-served stroke survivors, in the context of stroke selfmanagement. ${ }^{1}$ They used data from a randomized controlled pilot study, 2,3 and exploited logistic regression for constructing models able to predict health behaviors and outcomes. They found that programs empowering the patients and enhancing their involvement in religious activities as well as interventions focused on depression treatment could be particularly useful for improving patients' health behaviors.

Since cardiovascular diseases have a tremendous burden and represent an important target in the field of Public Health, it is very important to have an integrated bio-psycho-social model which could serve as a translational framework for designing and implementing ad hoc psycho-social interventions.

Under-served ethnic minorities are particularly vulnerable since they experience disparities and inequities in accessing health services, and have a susceptible genetic and biological makeup. 4 Moreover, ethnic minority patients have particular beliefs about their own diseases and a knowledge of these healthrelated beliefs as well as of perceived barriers could constitute an advancement in the field. Edelman et al. 5 found a correlation between acculturation and traditional cardiovascular risk factors and health behaviors. In particular, some health beliefs were considered as an obstacle in adopting protective behaviors and having regular preventive screening and routine check-ups. Other scholars have confirmed these findings and shown further correlations between acculturation and quality of life, perceived well-being and health locus of control (LOC). ${ }^{6}$

Depression, another variable studied by Robertson et al., is typically encountered among ethnic communities and could be associated with acculturation, deriving from the feeling of isolation or discrimination, and from a lack of integration in the new social context. Other explanations could be difficulties in speaking a new language and communicating with the others, poor economic conditions, psycho-social distress and the generational gap. ${ }^{7}$

Summarizing, a typical aspect of nonWestern patients is their attitude to conceive diseases as a holistic concept and to embed and incorporate spiritual and religious components in the nursing and health-care delivery. For example, prayer is deeply rooted among ethnic communities and is used by most patients suffering from chronic diseases, such as cancer and chronic heart failure (CHF). 8,9 But religiosity does not reduce only to prayers. Religiousness and spirituality, indeed, are very broad categories which include the creeds, the rituals, the transcendental conceptions, as well as their inner incorporation and personalized ways of living and practicing them, and spiritual inclinations.

These categories can be used as predictors of well-being and health outcome in patients with CHF.10 Moreover, spirituality has been found to modulate insulin resistance, inflammatory proteins such as TNF, interleukins (namely, IL6, IL10 and their ratio), metabolism (glucose plasma level and blood lipids), physiological parameters like blood pressure and heart rate. ${ }^{11,12}$ Since ethnic minorities are particularly vulnerable, exhibiting higher lipoprotein(a) levels, tissue-type plasminogen activator, high prevalence of diabetes mellitus and overweight/obesity and other metabolic disorders, ${ }^{9}$ interventions which incorporate spiritual practices for motivating patients to adopt health behaviors are particularly clinically relevant.

Spirituality modulates not only biological variables, but also psychological ones, such as depression and psychological acculturative distress. ${ }^{13,14}$ Religiosity could make patients more reflective about their diseases and could have an impact on their illness cognitions, perception of symptoms burden and quality of life. 15,16 For all these reasons, incorporating spiritual interventions is useful and meaningful also because taking into account patients' explanatory models could enable physicians to modulate psychosocial, behavioral aspects besides physiological ones and thus result more effective than traditional approaches. ${ }^{9}$ Moreover, as Robertson et al. have shown in their article, there is a strong need of culturally sensitive and tailored programs, 17 specifically targeted for under-served ethnic minorities. 18

\section{References}

1. Robertson SM, Huddleston C, Porter B, et al. Self-care self-efficacy, religious participation and depression as predictors of poststroke self-care among underserved
Correspondence: Nicola Luigi Bragazzi, School of Public Health, Department of Health Sciences (DISSAL), University of Genoa, Via Pastore 1, 16132 Genoa, Italy.

Tel: +39.010 .353 .7664 - Fax: +39.010 .353 .7669 .

E-mail: robertobragazzi@gmail.com

Received for publication: 5 May 2014.

Accepted for publication: 6 May 2014.

This work is licensed under a Creative Commons Attribution NonCommercial 3.0 License (CC BYNC 3.0).

(C)Copyright N.L. Bragazzi, 2014

Licensee PAGEPress, Italy

Health Psychology Research 2014; 2:1641

doi:10.4081/hpr.2014.1641

ethnic minorities. Health Psychol Res 2013;1:e13.

2. Evans-Hudnall G, Stanley MA, Foreyt JP, Sander AM. Self-management in acute care: are we starting risk reduction efforts too late? J Behav Med 2012 [In press].

3. Evans-Hudnall GL, Stanley MA, Clark AN, et al. Improving secondary stroke self-care among underserved ethnic minority individuals: a randomized clinical trial of a pilot intervention. J Behav Med 2014;37: 196-204.

4. Carson JA, Michalsky L, Latson B, et al. The cardiovascular health of urban African Americans: diet-related results from the genes, nutrition, exercise, wellness, and spiritual growth (GoodNEWS) trial. J Acad Nutr Diet 2012;112:1852-8.

5. Edelman D, Christian A, Mosca L. Association of acculturation status with beliefs, barriers, and perceptions related to cardiovascular disease prevention among racial and ethnic minorities. J Transcult Nurs 2009;20:278-85.

6. Finch BK, Hummer RA, Reindl M, Vega WA. Validity of self-rated health among Latinos. Am J Epidemiol 2002;155:755-9.

7. Tirodkar MA, Baker DW, Makoul GT, et al. Explanatory models of health and disease among South Asian immigrants in Chicago. J Immigr Minor Health 2011;13: 385-94.

8. Ross LE, Hall IJ, Fairley TL, et al. Prayer and self-reported health among cancer survivors in the United States, National Health Interview Survey, 2002. J Altern Complement Med 2008;14:931-8.

9. Tirodkar MA, Baker DW, Khurana N, et al. Explanatory models of coronary heart disease among South Asian immigrants. Patient Educ Couns 2011;85230-6.

10. Park CL, Lim H, Newlon M, et al. Dimensions of religiousness and spirituality as predictors of well-being in advanced 
chronic heart failure patients. J Relig Health 2014;53:579-90.

11. Holt-Lunstad J, Steffen PR, Sandberg J, Jensen B. Understanding the connection between spiritual well-being and physical health: an examination of ambulatory blood pressure, inflammation, blood lipids and fasting glucose. J Behav Med 2011;34:477-88.

12. Chaya MS, Ramakrishnan G, Shastry S, et al. Insulin sensitivity and cardiac autonomic function in young male practitioners of yoga. Natl Med J India 2008;21:21721.

13. Bekelman DB, Parry C, Curlin FA, et al. A comparison of two spirituality instruments and their relationship with depression and quality of life in chronic heart failure. $\mathrm{J}$ Pain Symptom Manage 2010;39:515-26.

14. Warber SL, Ingerman S, Moura VL, et al. Healing the heart: a randomized pilot study of a spiritual retreat for depression in acute coronary syndrome patients. Explore (NY. 2011;7:222-33).

15. Karademas EC. Illness cognitions as a pathway between religiousness and subjective health in chronic cardiac patients. J Health Psychol 2010;15:239-47.

16. Bekelman DB, Rumsfeld JS, Havranek EP, et al. Symptom burden, depression, and spiritual well-being: a comparison of heart failure and advanced cancer patients. J Gen Intern Med 2009;24:592-8.

17. Ai AL, Rollman BL, Berger CS. Comorbid mental health symptoms and heart diseases: can health care and mental health care professionals collaboratively improve the assessment and management? Health Soc Work 2010;35:27-38.

18. Williams ED, Nazroo JY, Kooner JS, Steptoe A. Subgroup differences in psychosocial factors relating to coronary heart disease in the UK South Asian population. J Psychosom Res 2010;69:379-87. 